\title{
A cost-benefit analysis of COVID-19 lockdowns in Australia
}

\author{
Martin Lally ${ }^{1}$
}

Accepted: 8 December 2021 / Published online: 28 January 2022

(c) Monash University 2021

\begin{abstract}
This paper conducts a cost-benefit analysis of Australia's Covid-19 lockdown strategy relative to pursuit of a mitigation strategy in March 2020. The estimated additional deaths from a mitigation strategy are 11,500 to 40,000, implying a Cost per Quality Adjusted Life Year saved by locking down of at least 11 times the generally employed figure of $\$ 100,000$ for health interventions in Australia. The lockdowns do not then seem to have been justified by reference to the standard benchmark. Consideration of the information available to the Australian government in March 2020 yields a similar ratio and therefore the same conclusion that lockdown was not warranted. If Australia experiences a new outbreak, and cannot contain it without resort to a nationwide lockdown, the death toll from adopting a mitigation strategy at this point would be even less than had it done so in March 2020, due to the vaccination campaign, lessons learned since March 2020, and because the period over which the virus would then inflict casualties would now be much less than the period from March 2020. This would favour a mitigation policy even more strongly than in March 2020. This approach of assessing the savings in quality adjusted life years and comparing them to a standard benchmark figure ensures that all quality adjusted life years saved by various health interventions are treated equally, which accords with the ethical principle of equity across people.
\end{abstract}

Keywords Covid-19 $\cdot$ Lockdowns $\cdot$ Cost-benefit analysis $\cdot$ Australia

\section{Introduction}

As with most other countries, in early 2020 and in response to Covid-19, Australia's federal and state governments implemented substantial general restrictions on mobility and economic activities involving the closure of non-essential businesses and confinement of the general public to their homes except for defined purposes ("lockdowns"). Since then, the restrictions have been substantially relaxed, but with

Martin Lally

lallym@xtra.co.nz

1 Capital Financial Consultants Ltd, 52 Friend St, Karori, Wellington 6012, New Zealand 
temporary reinstatements in different parts of the country. This paper conducts a cost-benefit analysis (otherwise called a cost-effectiveness analysis) of this lockdown strategy relative to a milder strategy involving case isolation, quarantining of members of their households, limiting large gatherings, social distancing in public spaces, border controls, and restrictions targeted at only high-risk groups ("mitigation"). This alternative was selected because it was the most widely contemplated alternative to lockdowns and could be expected to involve significantly lower costs. The population of concern is that of Australia. The Covid-19 deaths estimated are those over the period until the end of 2021 (on the basis that mass vaccination will be completed by then and therefore any case for lockdowns will cease at that point). The costs examined are society-wide costs without limit on the time horizon over which they are incurred because they can extend beyond the point at which lockdowns cease (but constrained by the difficulties in estimating longer term costs).

The paper commences by examining the optimal decision in March 2020 using data available as at 28 June 2021. It then considers the optimal decision based on information available at the time of the initial lockdown decision. Finally, it considers the optimal course of action now if a new outbreak occurs that cannot be contained without resort to lockdowns.

\section{The costs and benefits of lockdowns in March 2020}

\subsection{Deaths}

The primary intended benefit of lockdowns is a reduction in deaths. ${ }^{1}$ The deaths attributed to Covid-19 under the adopted lockdown policy have been about 1000 to date. ${ }^{2}$ Much less clear is what the death toll would have been under a mitigation policy. In mid March 2020 the Australian government estimated that, without lockdowns, up to $60 \%$ of the population would be infected and $1 \%$ of these would die, leading to up to 150,000 deaths. ${ }^{3}$ Shortly afterwards, in late March 2020, Blakely and Wilson (2020) estimated deaths from an eradication (lockdown) policy at 5000, those from a mitigation strategy at 25,000-55,000, and a worst-case scenario of 134,000 arising from no mitigation measures and $60 \%$ of the population then being infected. Subsequent estimates by Bailey and West (2020), drawing upon analysis by Moss et al. (2020) using data to 31 March 2020, involved 27,000 deaths under eradication (lockdown), 141,000 deaths under mitigation, and 287,000 deaths with

\footnotetext{
1 Reducing stress on the hospital system is often mentioned as a further purpose, but reducing this stress manifests itself primarily in reduced deaths anyway.

2 More deaths may occur in the future as a result of the lockdown policy pursued to date, such as those due to mental health problems, substance abuse and delayed diagnoses of existing conditions. At this point, quantification of these additional deaths is not feasible. In addition, unless otherwise stated, the word "deaths" means deaths occurring earlier than would have otherwise have occurred as a result of Covid-19.

3 See https://www.smh.com.au/politics/federal/australia-prepares-for-50-000-to-150-000-coronavirusdeaths-20200316-p54amn.html.
} 
no mitigating actions. Subsequent estimates by Holden and Prescott (2020) involved the government "allowing enough people to get infected to result in herd immunity", leading to $90 \%$ of the population being infected, and $1 \%$ of these dying, yielding 225,000 deaths. Subsequent estimates by Kompas et al. (2020, pp. 8-9) using data to 1 June 2020 involved 100 deaths from adoption of the suppression measures actually adopted, 35,000 if implementation had been delayed by 28 days, and 260,000 if no actions were taken by government or individuals. Blakely et al.'s (2020) estimates use mortality rates by age group from the Ferguson et al (2020) study in the UK. These in turn are based upon an epidemiological model in which each infected individual is estimated to infect $R$ others (the reproduction rate) and this process extrapolated until so many people are infected that the virus dies out for lack of new targets. The estimates of Bailey and West (2020), derived from Moss et al. (2020), and those of Kompas et al. (2020), share this crucial feature.

Amongst these predictions, only those considering both mitigation and lockdown strategies are relevant: 20,000 to 50,000 additional deaths by Blakely and Wilson (2020), and 114,000 by Bailey and West (2020). However, in both of these models, the estimated deaths under lockdown $(5000$ and 27,000) are far in excess of the actual deaths incurred to date under lockdown, and this implies that their estimates of the additional deaths under mitigation will also be far too high. In addition, the death rate estimated by Bailey and West under a mitigation policy (141,000 deaths, which is 5500 per 1 million of Australia's population of $26 \mathrm{~m}$ ) is vastly in excess of the death rate per 1 million of population to date in any European country pursuing a mitigation policy or any alternative. ${ }^{4}$ In addition, both of these models do not allow for the fact that, as the number of deaths rises, people will react by engaging in more and more protective actions that will reduce the future death rate, such as hand washing, mask wearing, reducing social interactions, and working from home.

In view of these empirical and theoretical deficiencies, I estimate the additional deaths under a mitigation strategy rather than a lockdown strategy in Australia by examining the death rates in other countries. Foster (2020) uses the death rate in Sweden to estimate the additional Australian deaths under a mitigation approach at 10,000 (at the time of her analysis in August 2020). However, Sweden was not the only mitigator; Iceland, Finland and Latvia did likewise. Even better would be to use the full set of countries with reliable data. One such approach would be to conduct a cross-country regression of death rates on variables found to influence such death rates, and include amongst the explanatory variables the strength of government restrictions. The coefficient on this latter variable would then provide an estimate of how many extra deaths would arise if the restrictions were less onerous. Chaudhry et al. (2020) examines the 50 countries with the highest case counts as at 1 April 2020, and regresses cross-country death rates per 1 million of population (up to 1 May 2020) on a number of independent variables, including various measures of government intervention. They find that none of these latter variables

\footnotetext{
${ }^{4}$ Within Europe, the mitigating countries have been Iceland, Finland, Latvia and Sweden, with death rates per 1 million of population up to 28 June 2021 of $87,175,1342$ and 1435 respectively. All death rate data in this paper are drawn from https://www.worldometers.info/coronavirus/.
} 
were statistically significant. Gibson (2020) conducts a similar analysis, using the 34 OECD member countries, death rates up to 18 August 2020, and various independent variables including the average level of government restrictions over the period of the crisis. ${ }^{5}$ He finds that policy stringency (averaged over the whole crisis period) is not statistically significant in explaining cross-country variation in death rates (ibid, Table 2). He also examines average stringency both before and after the estimated infection peak for each country, and finds mild statistical significance for average stringency prior to the estimated infection peak along with a negative coefficient (ibid, Table 2). He also uses average stringency in other countries within the same OECD group as an instrumental variable, to test for reverse causality between stringency and death rates, and finds no evidence of reverse causality. Hale et al. (2020b) conduct a similar analysis, using 170 countries and data to 27 May 2020. They find that both the speed of government response (number of days from the first reported case till the government restrictions reach 40 on the Hale et al. 2020a Stringency index) and the severity of the restrictions (using the Stringency index of Hale et al. 2020a) affect death rates in the expected way. Argarwal et al. (2021) examine excess deaths (actual less those predicted using pre-pandemic data) in 43 countries and all 50 US states following Shelter-in-Place orders, and find that excess deaths do not decline following such orders, except for all of the island nations and states in their data set (which include Australia).

Given the actual or probable unreliability of data from many countries, it is desirable to limit the analysis to countries for which the data is likely to be very reliable. It is also desirable to eliminate countries with federal systems, in which restrictions varied by state or province, because the Hale et al. (2020a) data is only available at the country-level. This leaves European countries and the East Asian democracies (Japan, South Korea, Taiwan, Singapore, plus Hong Kong). Hale et al. (2020a) have constructed a set of indexes, which assign a daily score to each country for the severity of their restrictions imposed by government, ranging from 0 to 100 and taking account of different types of restrictions. I use their Stringency Index, which takes account of 8 different types of government restrictions. ${ }^{6}$ Death rates per 1 million of population are drawn from https:/www.worldometers.info/coronavirus/. All five East Asian countries have very low death rates regardless of the severity of restrictions, and the possible reasons (a culture of mask wearing, not shaking hands, compliance with government directives, extensive contact tracing and testing, and pre-existing immunity) are or were not applicable to the same degree in Australia. So, I use only the European countries, of which there are $33 .^{7}$ They are similar (on

\footnotetext{
5 The latter is quantified using the Stringency Index of Hale et al. (2020a), which assigns a daily score to each country for the severity of their restrictions imposed by government, ranging from 0 to 100 and taking account of different types of restrictions: see https://covidtracker.bsg.ox.ac.uk/ for the data.

6 See https://covidtracker.bsg.ox.ac.uk/ for the data. Their other indexes produce similar results.

7 Malta is excluded because Hale et al. (2020a) does not include data on them. In addition the political entities with very small populations (under 100,000) are all excluded because many of the data sources used for this analysis do not provide data on them. For example, Hale et al. (2020a) does not include data on the Faeroe Islands, Monaco and Liechtenstein, whilst the "List of Countries by Age Structure" does not include data on Andorra, San Marino, Gibraltar, and Greenland.
} 
average) to Australia in ethnicity, cultural norms, demographics, GDP per capita, and the quality of their health care systems. By contrast, they have generally colder temperatures and a smaller proportion of their populations from East Asia (thereby benefiting less from any pre-existing immunity amongst East Asians).

In using the Stringency Index, there is a choice of the average and maximum values, and both have merits. The maximum reflects only government policy on one day whilst the average (crudely) takes account of it over the entire period of the crisis. However, a given average value could arise from a wide range of different policies. An extreme case of this would arise if one country adopted its maximum stringency index value of 100 on the first day, retained it for 6 weeks and then removed all restrictions because eradication had been achieved, whilst a second country maintained a stringency index value of 50 throughout the 12 weeks of the analysis. Both would have an average Stringency of 50, but would have adopted entirely different policies. I therefore use both the average and maximum values.

Death rates are likely to be affected by many variables other than the severity of government restrictions, and it is desirable to include them. I consider

(a) Population density (higher values increase the transmission rate of the virus),

(b) The date of the first death (in days after the first recorded death on 15 February in France), because later dates provide more time for people, doctors and their governments to learn from others and adjust their behavior, ${ }^{8}$

(c) Population (higher values provide a higher pool of virus targets before restrictions on movements across national borders limit the movement of people and therefore the transmission of the virus),

(d) GDP per capita (as a proxy for the quality of the health care system),

(e) The population proportion over 65 (higher values imply a larger proportion of the population in the high risk group),

(f) The average household size (higher values increase the pool of virus targets before restrictions on movements across households limits interactions and therefore the transmission of the virus),

(g) The number of nursing and elderly home beds per 100,000 of population (because higher values implies a higher concentration in the high-risk group, which increases or lowers the death rate depending upon the effectiveness of the quarantine and other procedures),

\footnotetext{
${ }^{8}$ A closely related variable is the number of days from the date on which the Stringency Index reached 54 (the lowest of the cross-country maxima and therefore defined for all countries) until the date of the first death, because higher values indicate a faster response by a government to the crisis. Hale et al. (2020b) use a similar variable. Each of these two variables is highly statistically significant and the $R^{2}$ results from them are almost identical, but that from 'Date of First Death' are slightly better. I therefore report only the results from the use of 'Date of First Death'.
} 
(h) The proportion of the adult population who are obese,

(i) Average temperature, and

(j) Influenza intensity in the last two influenza seasons. ${ }^{9}$

Mass vaccination commenced in Europe in December 2020. Since the speed of vaccination is likely to be a significant explanatory variable from that point, I conduct the analysis described above using data only to 30 December 2020. The first two variables are statistically significant, and substantially raise the adjusted $R^{2}$, whilst the last eight variables (added and tested separately) are not statistically significant and their inclusion each lowers the adjusted $R^{2}$. I therefore retain only the first two variables. Regressing the death rate per 1 million of population $(D)$ up to 30 December on the maximum Stringency Index value $(S)$, the population density $(P D$, in millions per 1000 square miles), and date of first death (FD, in days from 15 February) yields the following result:

$$
D=273.9+7.34 S+473.1 P D-12.3 F D
$$

The $R^{2}$ is 0.29 , and the $p$ values are $0.66,0.27,0.10$ and 0.10 respectively. The coefficient on $S$ is statistically insignificant and the sign on it is 'wrong' (positive rather than negative). ${ }^{10}$ Even using the lower bound on the $95 \%$ CI for $S$ of -6.05 , the expected increase in a country's death toll from moving from the most restrictive policy (Bosnia with $S=100$ ) to the least restrictive policy (Iceland with $S=54$ ) would be to raise its death rate by only $6.05^{*}(100-54)=278$ per $1 \mathrm{~m}$ of population. So, the evidence for government restrictions substantially reducing the death rate is minimal in general.

This result may seem counterintuitive, but explanations are available. One possibility is that reverse causality applies, i.e., the choice of policy is influenced by the death rate as well as the death rate being affected by the policy choice. The Appendix investigates this possibility and concludes that it does not operate. A second possibility is that, even without government restrictions, people will take

\footnotetext{
9 For the population of countries, see the last column of https://www.worldometers.info/coronavirus/. For area of countries, see third column of https://en.wikipedia.org/wiki/List_of_countries_and_depen dencies_by_area. For GDP per capita of countries, see the first column (IMF data) of https://en.wikip edia.org/wiki/List_of_countries_by_GDP_(nominal)_per_capita. For the population proportion over 65, see https://en.wikipedia.org/wiki/List_of_countries_by_age_structure. For average household size, see https://www.un.org/en/development/desa/population/publications/pdf/ageing/household_size_and_ composition_around_the_world_2017_data_booklet.pdf, pp. 20-24, except for Cyprus, which comes from https://population.un.org/Household/index.html\#/countries/196. For the number of nursing and elderly home beds per 100,000 of population, see https://gateway.euro.who.int/en/indicators/hfa_4905100-nursing-and-elderly-home-beds-per-100-000/, which does not contain data for Bosnia, Cyprus and Portugal so these numbers were estimated from those for Croatia, Greece and Spain respectively. For the obesity proportion, see https://worldpopulationreview.com/country-rankings/obesity-rates-by-country. For average yearly temperature, see https://en.wikipedia.org/wiki/List_of_countries_by_average_yearly_ temperature. For flu intensity, see Appendix to Hope (2020). The dates of the first deaths come from https://www.worldometers.info/coronavirus/.

${ }^{10}$ Using the average Stringency Index (from the first European death on 14 February to 30 December) instead of the maximum Stringency Index also yields a coefficient that is positive and statistically insignificant.
} 
actions to lower their risks in a pandemic and the incremental effect of government actions may then be too little to be statistically significant. A third possibility is that lockdowns will in some cases increase the risk of transmission to highrisk individuals, and this at least partly offsets the reduction in risks achieved in other ways. For example, lockdowns will have caused some young people to return to live with their older parents, perhaps because of the loss of their job or closure of the university they were attending, and if already infected to thereby infect their parents, who are at much greater risk of death. A fourth possibility is that some of the European lockdowns were not instituted quickly enough to be effective, and all of those that were instituted quickly enough were relaxed before elimination had been achieved (because their land borders were too porous to achieve elimination) leading to a resurgence in cases when the lockdowns were relaxed.

Nothing in the analysis so far precludes the possibility that some of these European countries experienced a lower death rate as a result of lockdowns, and the last point offers an explanation for that outcome: being an island and instituting the lockdown quickly. To assess whether Australia was in this category, I proceed as follows. The European data consists of countries that adopted mitigation strategies, and those that adopted lockdown strategies that in general performed no better or worse in their death rate. It follows that the European data are equivalent to that from a set of countries that in general pursued mitigation. So, an estimate of the Australian death rate under mitigation would be the average European death rate (680 per 1 million of population as at 30 December), corrected for differences in variables that are statistically significant in explaining the death rate. For Europe, these are population density $(P D)$ and date of first death $(F D)$, and the resulting model using death rate data to 30 December is

$$
D=887+497 P D-12.9 F D
$$

The $R^{2}$ is 0.26 and the $p$ values on the coefficients are $0.002,0.09$ and 0.09 respectively. Substitution of Australia's values for the regressors, of $P D=0.009$ and $F D=15$, yields an estimated death rate $D$ under mitigation of 699 per 1 million of population. This is significantly more than the death rate actually experienced by Australia over the same period (35 per 1 million of population), and therefore suggests that its lockdown policy did lower its death rate.

This analysis uses data from European countries, because the quality of the data is judged to be sufficient, and conservatively excludes East Asian democracies (with very low death rates regardless of government policy) because cultural norms etc. may differ significantly from Australia. The next best source of data appears to be that from the Americas, but with the exclusion of the US and Canada (because they are federal systems with variation in policy by state) and exclusion also of Cuba, Nicaragua and Venezuela (because authoritarian regimes are likely to deliberately understate deaths). Countries with less than 50,000 people are also excluded because death rates expressed per 1 million of population (as the data source does) are only then expressible in multiples of 20 or more. Across the countries for which both Hale et al. (2020a) provides the Stringency data and 
the www.worldometers.info website provides death rate data, there are 28 such countries: Brazil, Argentina, Colombia, Mexico, Peru, Chile, Ecuador, Bolivia, Panama, Dominican Republic, Costa Rica, Guatemala, Honduras, Paraguay, El Salvador, French Guyana, Jamaica, Haiti, Trinidad and Tobago, Suriname, Aruba, Guyana, Belize, Uruguay, Cayman Islands, Barbados, Bermuda, and Dominica. Unlike the European data, population density and date of first death are not statistically significant, but the following two regressors are statistically significant:

(a) Population (higher values provide a higher pool of virus targets before restrictions on movements across national borders limit the movement of people and therefore the transmission of the virus),

(b) Having no land borders with other countries (water barriers rather than land borders better restrict the flow of people and hence the virus into a country).

If the maximum Stringency index is added, it is not statistically significant and the estimated coefficient on it is positive rather than the expected negative. With $P$ denoting population in millions and $I$ denoting no land borders ( 1 if so and 0 otherwise), the model exclusive of $S$ is thus:

$$
D=434+3.47 P-313 I
$$

The $R^{2}$ is a respectable 0.43 , and the $p$ values on the three coefficients are 0 , 0.01 and 0.01 respectively. Substitution of Australia's values for the regressors, of $P=26$ and $I=1$, yields an estimated death rate under mitigation of 211 per 1 million of population. This estimate uses data from only the Americas.

If the European and Americas data are pooled, $P, I$ and date of first death (FD) are statistically significant at the $10 \%$ level, with all coefficients having the expected signs. Addition of $S$ yields a coefficient that is not statistically significant, and with the wrong sign. The resulting model exclusive of $S$ is thus:

$$
D=860+2.4 P-333 I-8.6 F D
$$

The $R^{2}$ is a respectable 0.36 , and the $p$ values on the four coefficients are 0 , $0.07,0.02$ and 0.02 respectively. Substitution of Australia's values for the regressors, of $P=26, I=1$, and $F D=15$, yields an estimated death rate under mitigation of 460 per 1 million of population. This estimate uses data from both Europe and the Americas.

Across these three models (2), (3) and (4), the estimated death rate for Australia under a mitigation policy is 211 to 699 per 1 million of population up to 30 December 2020. With 26 million people in Australia, this implies 5000-18,000 deaths in Australia up to 30 December had a mitigation policy been pursued. The estimate of 18,000 uses the best quality data (from Europe) but is likely to be too high because Australia is an island, and this reduces its death rate, but there are too few islands in the European data (only two) for the dummy variable "Island" to be statistically significant and therefore warrant inclusion in Eq. (2). Since Australia's actual Covid-19 deaths to 30 December 2020 (35 per 1 million of population) were much less than even the lowest of these estimates using foreign 
data and accounting for exogenous factors that affect death rates, this suggests that Australia's lockdowns did reduce its Covid-19 death toll. This is consistent with Argarwal et al.'s (2021) conclusion for Australia. I therefore proceed on this basis, and it gives the Australian lockdowns the benefit of the doubt.

These estimates presume that Covid-19 deaths are accurately recorded. However, some Covid-19 deaths may be mistakenly attributed to another cause, or deaths from other causes mistakenly attributed to Covid-19, with the latter error possible simply because most victims have co-morbidities. By analogy, if a person is shot in the heart and then the head, and then dies, the cause of death may not be the head shot. In addition, lockdowns discourage or prevents some people suffering from non Covid-19 conditions from seeking medical attention, leading to some deaths in lockdown countries that would not otherwise have occurred, and these should be included in the incremental deaths from lockdown. In addition, mitigation increases the load on hospitals, leading to more deaths from other causes (through lack of care) in mitigation countries, and these should be included in the incremental deaths from mitigation. An estimate of the Covid-19 deaths that accounts for all of these phenomena is the actual deaths in 2020 less the predicted number without Covid-19 ("Excess Deaths"). The Euromomo Network has done so and estimated the number of deaths across 18 European countries progressively through 2020, 2019 and 2018 relative to a prediction ("baseline"). The Excess Deaths for 2020 exhibit sharp increases in March-April and November-December, consistent with the pandemic. The Excess Deaths to 31 December relative to the baseline are 290,000 for 2020 (from 15 February when the first Covid-19 death occurred in any of these 18 countries), 70,000 for 2019 and 115,000 for 2018. ${ }^{11}$ By contrast, the deaths attributed to Covid-19 across these 18 countries (to 31 December) were $334,000 .{ }^{12}$ Thus, if the baseline were used, the Excess Deaths in 2020 would be 290,000 and this differs from the 334,000 deaths attributed to Covid-19 by $15 \%$. However, the baseline is an imperfect prediction, as evidenced by the results for 2018 and 2019 (which would be zero if the predictions were accurate). This is simply a consequence of the fact that deaths in these countries in a typical year are about 3 million, so that the prediction error of 115,000 for 2018 is a small proportion. ${ }^{13}$ All of this suggests that the 334,000 deaths attributed to Covid-19 in these countries are approximately correct.

Turning now to further deaths from 30 December 2020, these are likely to be significantly influenced by the speed of vaccination. However, even if a model could be developed to quantify this, the speed with which Australia would have vaccinated had it followed a mitigation strategy is indeterminable (and likely to be much faster than the speed with which it is vaccinating under its lockdown policy). So, the best available estimate of the additional deaths in Australia from 30 December

\footnotetext{
11 See https://www.euromomo.eu/graphs-and-maps\#excess-mortality.

12 The countries are Austria, Belgium, Denmark, Estonia, Finland, France, Greece, Ireland, Italy, Luxembourg, Malta, Netherlands, Norway, Portugal, Spain, Sweden, Switzerland and the UK.

13 See https://www.ined.fr/en/everything_about_population/data/europe-developed-countries/popul ation-births-deaths/.
} 
2020 under a mitigation strategy would seem to be that arising from applying the average ratio for Europe. Over the period from 30 December 2020 to 28 June 2021, the European deaths are $95 \%$ of those to 30 December, and the rate of deaths fell sharply towards the end of the period. This suggests that deaths from 30 December 2020 until the end of 2021 (at which point mass vaccination is likely to have been largely completed) will not exceed 1.5 times those to 30 December $2020 .{ }^{14}$

Applying this ratio of 1.5 to Australia, with estimated deaths to 30 December 2020 under a mitigation strategy of 5000 to 18,000 , yields 12,500 to 41,000 deaths to the end of 2021. By contrast, deaths to 28 June 2021 under a lockdown policy have been almost 1000. So, the extra deaths resulting from a mitigation policy rather than a lockdown policy are estimated to be 11,500 to 40,000 . By contrast, Blakely and Wilson (2020) predicted an extra 20,000 to 50,000 deaths.

\subsection{Quality adjusted life years}

In assessing the merits of health interventions, the standard methodology amongst health economists is to multiply the expected lives saved from a health intervention by the average residual life span of the victims without intervention, to yield the "Life Years" saved by the intervention, followed by some discount if the quality of these life years saved would be less than that of a normal healthy person. The result is called the Quality Adjusted Life Years (QALY) saved by the intervention, which is then compared to a benchmark figure.

Kompas et al. (2020, p. 8) estimates the average residual life expectancy of the victims at 6.9 years, by comparison of the average age of the Australian victims (75.6) with the life expectancy of Australians at birth (82.5). Such an estimate does not recognize that the set of people who reach the age of 75.6 excludes those who have died at an earlier age and therefore this set will have an average residual life expectancy greater than 6.9 years. The corrected estimate will then be too high because it does not recognize that Covid-19 victims are unusually unwell relative to those of age 75.6 in general. Blakely and Wilson (2020) adopt an average residual life expectancy for the victims of 5 years, but provide no supporting evidence. Foster (2020) does likewise.

Analysis of European data supports this figure of 5 years. I illustrate this with Sweden, which adopted a mitigation policy and incurred the highest death rate amongst European countries that did so. The age distribution of the Covid-19 victims is shown in the first two columns of Table 1, and the residual life expectancy (RLE) of Swedish people in each such age group is shown in the third column. Using these data, the average residual life expectancy of Swedish people with the

\footnotetext{
14 Mass vaccination will at best reduce rather than eliminate deaths, because some people are unresponsive to vaccines or will not consent to them. However, it is very unlikely that lockdowns would be pursued beyond this point. So, in assessing the merits of lockdowns and mitigation, the relevant deaths are those up to this point.
} 
same age distribution as the Covid-19 victims is 10.9 years. ${ }^{15}$ However, the Covid19 victims differ from Swedish people of the same age distribution in two very significant ways.

The first of these differences is that a large proportion of the victims were residents of nursing homes, whose average residual life expectancy without Covid-19 was very low and might be even lower than suggested by their ages. If so, conditioning on residency of a nursing home as well as age would reduce the average residual life expectancy of the victims. In respect of Sweden, Stern and Klein (2020, p. 5) estimate that $53 \%$ of the Covid-19 victims aged at least 70 were residents of nursing homes, and that their average residual life span without Covid-19 was only seven months (ibid, pp. 16-17). Conservatively treating this subset of victims as the oldest in Table 1, they represent the entire $85+$ group (47\%) plus additional victims in the 80-84 group constituting $6 \%$ of the entire set of victims (6/21 of that group). Replacing the residual life expectancy of these people by seven months ( 0.6 years), the average residual life expectancy calculated from the data in Table 1 would fall to 7.7 years as shown in the fourth column of Table $1 .{ }^{16}$ By contrast, if this nursing home group were spread through the $70+$ groups in proportion to the size of these groups, $28 \%$ would be in the $85+$ group, $13 \%$ in the $80-84$ group, and $13 \%$ in the 70-79 group. Replacing the residual life expectancy of these people by 0.6 years, the average residual life expectancy calculated from the data in Table 1 would fall to 6.4 years.

The second unusual feature of these Covid-19 victims is that they were unusually unwell, even for their age; virtually all had at least one co-morbidity, which is presumably well in excess of the rate for the general population of the same age distribution. ${ }^{17}$ A common such ailment was type 2 diabetes. The NHS (2018, Fig. 8) provides estimates for the increase in mortality risk from this disease (relative to the general population) by age and sex. Averaging over these categories, the increase is about $50 \%$. However the group of interest here excludes those in nursing homes, because the estimate for the residual life expectancy of these victims already reflects co-morbidities. This exclusion lowers the average age of the remaining victims, and

\footnotetext{
${ }^{15}$ See https://www.statista.com/statistics/1107913/number-of-coronavirus-deaths-in-sweden-by-agegroups/ and https://apps. who.int/gho/data/?theme=main\&vid=61600. The age distribution is only available in ten-year blocks whilst life expectancy is only available in 5 year blocks up to age 85 followed by an $85+$ group. So, Table 1 shows the number of victims in ten-year blocks up to age 80 as per the source data, the number of victims assigned to the 80-84 block is half of that reported in the 80-89 block, the other half of that block plus the $90+$ block is combined to form an $85+$ block, the life expectancies for the ten-year blocks up to age 80 are averaged over the data for each ten-year block, and the life expectancies for the last two blocks are as per the source data. The life expectancy data is also separately reported for males and females, unlike the age distribution of the victims, and the former data is therefore averaged over the sexes (since the Miles et al. 2020, data reveal that the sex split of the victims is close to $50 / 50$, at $56 \%$ men).

${ }^{16}$ The figure of 6.67 years in this column of the table is a weighted average of 0.6 years for the nursing home residents, with weight $6 / 21$, and 9.1 years for the rest.

${ }^{17}$ In respect of those dying in New York City up to 13 May 2020, and in those cases where the existing medical condition of the patient was known (no underlying condition or at least one underlying condition), 98\% had at least one underlying condition (the set of conditions includes diabetes, cancer, heart disease, lung disease, and hypertension). See https://www.worldometers.info/coronavirus/coronavirusage-sex-demographics/.
} 
Table 1 Residual life expectancy of Swedish Covid-19 victims

\begin{tabular}{llllll}
\hline Age group & Victims & RLE & RLE & RLE & RLE \\
\hline $0-9$ & 2 & 79.55 & 79.55 & $79.55(0.7)$ & $79.55(0.7)$ \\
$20-29$ & 10 & 60.25 & 60.25 & $60.25(0.7)$ & $60.35(0.7)$ \\
$30-39$ & 19 & 50.5 & 50.5 & $50.5(0.7)$ & $50.5(0.7)$ \\
$40-49$ & 45 & 40.8 & 40.8 & $40.8(0.7)$ & $40.8(0.7)$ \\
$50-59$ & 164 & 31.3 & 31.3 & $31.3(0.7)$ & $31.3(0.7)$ \\
$60-69$ & 406 & 22.4 & 22.4 & $22.4(0.7)$ & $22.4(0.7)$ \\
$70-79$ & $1268(22 \%)$ & 14.3 & 14.3 & $14.3(0.7)$ & 4.45 \\
$80-84$ & $1219(21 \%)$ & 9.1 & 6.67 & 4.72 & 2.80 \\
$85+$ & $2747(47 \%)$ & 6.3 & 0.6 & 0.6 & 2.14 \\
Average (years) & & 10.9 & 7.7 & 5.5 & 4.7 \\
\hline
\end{tabular}

suggests an increase in their mortality risk of about $80 \%$. In addition, a person with a residual life expectancy of 10 years (the average for the Covid-19 victims) would have a current mortality risk of about $5 \%$ over the next year, growing at about $11 \%$ per year compounded ${ }^{18}$ :

$$
R L E=.05(1)+(1-0.05)[.05(1.1)]((2)+(1-.05)[.05(1.1)(1.1)](3)+\cdots=9.52 y r s
$$

Raising this initial mortality risk by $80 \%$, from 5 to $9 \%$, along with the same growth rate of $11 \%$, reduces the residual life expectancy from 9.52 to 6.68 years, i.e., a reduction of $30 \%$. A similar percentage reduction applies to the average residual life expectancy of a group. As noted above, virtually all of the victims had at least one co-morbidity, and multiple co-morbidities would reduce the average residual life expectancy of a group by even more.

Allowing for this additional feature of the Covid-19 victims is simplified by the fact that virtually all Covid-19 victims had co-morbidities. So, the subset of Swedish victims from nursing homes have their residual life expectancy set as before at 0.6 years (which will also reflect their co-morbidities), and all others have their residual life expectancy reduced by (conservatively) 30\%. The results are shown in the penultimate column of Table 1, with the nursing home group conservatively assumed (as before) to be the oldest, and the last column of Table 1, in which the nursing home group is spread throughout the $70+$ groups in proportion to their sizes. ${ }^{19}$ The average residual life spans are 5.5 and 4.7 years respectively, and a good estimate would lie between these figures. So, starting with 10.9 years, the reduction is to 6.4-7.7 years to account for the nursing home group, and then to 4.7-5.5 years

18 Data from the Period Life Tables 2012-2014, Table 5: http://archive.stats.govt.nz/browse_for_stats/ health/life_expectancy/NZLifeTables_HOTP12-14/Data\%20Quality.aspx\#gsc.tab=0. The table gives medians rather than means and therefore is not directly usable here.

19 The figure of 4.72 years in the penultimate column of the table is a weighted average of 0.6 years for the nursing home residents, with weight 6/21, and 9.1 years for the rest. The figure of 2.80 in the final column is a weighted average of 0.6 years for the nursing home residents, with weight $13 / 21$, and 6.3 years for the rest. 
to additionally account for co-morbidities in the rest. This supports the estimate of Blakely and Wilson (2020) and Foster (2020), of 5 years.

The last step here is the discount to reflect the imperfect health of virtually all of these victims without Covid-19. Miles et al. (2020, p. 69) use $20 \%$ based on prevailing discounts for type 2 diabetes with and without additional problems. In particular, they cite Beaudet et al. (2020, Table 3), who favour a quality of life discount of $21 \%$ for Type 2 diabetes without complications, and substantial additional discounts for further problems including $9 \%$ for heart disease and $16 \%$ for stroke. These discounts in Beaudet et al. (2020) suggest that Miles et al.'s (2020) 20\% discount for an average Covid-19 victim is low. Consistent with this, Briggs (2020, Fig. 3) uses a discount of about $30 \%$ for Covid-19 victims, based upon norms arising from survey data from Szende et al. (2014). Furthermore, a large proportion of the victims were residents of nursing homes, for which the quality of life discount could reasonably be even higher. I adopt a conservative estimate of the discount, of $20 \%$.

A further step undertaken by Briggs (2020, Fig. 3) is to discount future QALY losses, and the reduction is substantial. Briggs does not disclose the discount rate used, but use of the yield on ten-year Australian government bonds (averaged over the period Feb 2020-Jan 2021, of 0.9\%) reduces the result in Table 1 above from 4.7 to 3.9 years. Since this does not seem to be standard practice amongst health economists, I do not incorporate this additional adjustment.

In conclusion, the QALYs saved by the Australian government pursuing lockdown rather than mitigation are estimated at $11,500 * 5 * 0.8=46,000$ to $40,000 * 5 * 0.8=160,000$.

\subsection{Expected GDP losses}

Turning now to the costs of the lockdown policy, I commence with the lost GDP because it is most amenable to quantification. Shortly before the pandemic arose, in December 2019, the Australian Treasury (2019, Table 1.2) forecasted Australia's real GDP growth rates for 2019-2020 till 2022-2023 at the rates shown in the first row of Table $1 .^{20}$ This is an estimate of growth in the absence of the pandemic. Arbitrarily designating 2018-2019 GDP as 100, the GDP results under this path are shown in the next row of the table. In May 2021 they released updates as shown in the third row of the table (Australian Treasury 2021, Table 1.2), with the implied GDP path in the fourth row. The last row of the table shows the difference between the two paths, which aggregates to 22.4 , i.e., $22.4 \%$ of Australia's 2018-2019 GDP. Since Australia's 2018-2019 GDP was \$1950b, this is $\$ 437 \mathrm{~b} .^{21}$ This estimate is conservative because the two real GDP forecast paths in Table 2 have not converged over the period for which the forecasts are available (out to mid 2025). By comparison, Pujol (2020, Table 1) reports estimates of this type from nine advanced economies that locked down, using data

\footnotetext{
20 The figures for 2023-2024 and 2024-2025 do not appear in the document, and are extrapolated from the series for comparison with the later forecasts, which do include 2023-2024 and 2024-2025.

21 The GDP figure comes from Table H1 on the website of the RBA: https://www.rba.gov.au/statistics/.
} 
from Consensus Economics, and the median loss is $25 \%$. In addition, GomezPineda (2020, Fig. 1) graphically presents annual estimates of this type for both advanced and developing economies (each averaged), and the accumulated losses over the 2020-2024 period are 25\% and 40\% respectively. Consistent with not discounting the QALYs, the GDP costs are also not discounted.

Some of these GDP losses of \$437b would have arisen without any Australian government-imposed lockdowns, because some people would have reduced their interactions with others anyway; for example, a foreigner electing not to make a trip to Australia that they would otherwise have made, or an Australian choosing to avoid cafes. Further losses would have arisen due to the additional actions of foreign governments; for example, foreign governments preventing or discouraging their citizens from making foreign trips. Further losses would have arisen if the Australian government had followed merely a mitigation strategy, which includes border closures. Finally, further losses would have arisen from the Australian government instead following a lockdown strategy. It is only the last category of these losses that can be attributed to the Australian government choosing a lockdown policy rather than a mitigation policy.

Estimating the proportion arising from this last category is difficult. Andersen et al (2020) examine the drop in consumer spending in the early stages of the pandemic in both Denmark (which adopted a lockdown policy) and Sweden (which adopted a mitigation policy). They find that the drop in Sweden was $86 \%$ of that in Denmark (25\% drop vs $29 \%$ drop), implying that $14 \%$ of the drop in Denmark was due to a lockdown rather than a mitigation policy. In a similar study (Goolsbee and Syverson 2020) examine adjoining US counties with one area subject to lockdown and the other not; the drop in consumer activity in the latter area was $88 \%$ of the former, implying that only $12 \%$ was due to the lockdown. Doti $(2021$, p. 120) conducts a cross-sectional study of all US states and concludes that $75 \%$ of the GDP losses were due to state government level interventions (from a Stringency Index of zero to the state average of 42 ), i.e., $2.2 \%$ out of $3 \%$. Since the latter variation in the Stringency Index values approximates the difference between mitigation and extreme rather than an average lockdown, this suggests that an average lockdown would explain $1.1 \% / 1.9 \%=57 \%$ of the GDP loss. Aum et al. (2020) estimate the effect of increased infections upon the unemployment rate in Korea (which did not lock down), the US and UK (which did), and conclude that the effect is twice as great in the US and UK, leading to the conclusion that lockdowns explain $50 \%$ of the loss of employment. In a much broader study, the IMF (2020, Chapter 2) examined 28 countries and concluded that lockdowns contributed $40 \%$ of the reduction in 'Google Mobility Data' in advanced economies, which is a proxy for the GDP loss. In a similar study, Caselli et al. (2021) found that the reduction was $44 \%$ using the same data source (ibid, Fig. 4) and also 44\% using job postings data (ibid, Fig. 5), all for advanced economies. In an approach directly comparable with Table 2 above, Pujol (2020, Table 2) presents estimates of the GDP losses for nine advanced economies that locked down (US, Canada and seven Western European economies), and two that did not (Sweden and Japan); the median of the first group is $25 \%$ and that of the latter is $16 \%$, which implies that $36 \%$ of the loss is due to lockdowns. 
Table 2 GDP forecasts

\begin{tabular}{lccccccc}
\hline & $19-20$ & $20-21$ & $21-22$ & $22-23$ & $23-24$ & $24-25$ & Sum \\
\hline Dec 2019 Forecasts & $2.25 \%$ & $2.75 \%$ & $3.0 \%$ & $3.0 \%$ & $3.0 \%$ & $3.0 \%$ & \\
Implied GDP & 102.3 & 105.1 & 108.2 & 111.5 & 114.8 & 118.2 & \\
June 2021 Forecasts & $-0.2 \%$ & $1.25 \%$ & $4.25 \%$ & $2.5 \%$ & $2.25 \%$ & $2.5 \%$ & \\
Implied GDP & 99.8 & 101.0 & 105.3 & 108.0 & 110.4 & 113.2 & \\
Shortfall & 2.5 & 4.1 & 2.9 & 3.5 & 4.4 & 5.0 & 22.4 \\
\hline
\end{tabular}

In summary, these estimates of the proportion of GDP losses due to an average lockdown relative to mitigation range from 12 to $57 \%$. The best estimates here are the last three $(40 \%, 36 \%$ and $44 \%)$, because they each cover a wide range of countries. I adopt the median estimate of 40\%. Applying it to the Australian GDP loss of $\$ 437 \mathrm{~b}$ yields a loss due to the lockdowns of at least $\$ 175 \mathrm{~b}$.

Amongst other Australian analyses, Foster (2020) and Holden and Prescott (2020) also estimate the GDP losses by reference to forecast growth rates, but do not accumulate the losses over the entire period of the shortfall. By contrast, Kompas et al. (2020, pp. 11-14) estimates the GDP losses for each day of the lockdown, scales this up for 8 weeks of lockdown (56 days) to yield $\$ 52 \mathrm{~b}$, and then assumes a four month transition path back to "normal", yielding a GDP loss of up to $\$ 120 \mathrm{~b}$. However, the Australian Treasury could reasonably be presumed to have far greater expertise in predicting GDP (see Table 2 above). Some analyses assess costs and benefits only during the period of lockdown, which is equivalent to (implausibly) assuming that GDP immediately reverts to the pre-pandemic forecast path upon cessation of the lockdown (for example, Scherbina 2021, Fig. 4).

\subsection{Cost per QALY saved}

In summary, the QALYs saved by locking down rather than mitigating are estimated at 46,000 to 160,000 whilst the associated GDP losses are expected to be at least $\$ 175 \mathrm{~b}$. If these GDP losses were the only cost of lockdowns, the cost per QALY saved would then be at least $\$ 1.09 \mathrm{~m}$ as follows:

$$
C=\frac{\$ 175 b}{160,000}=\$ 1,090,000
$$

I now attempt to quantify all of the additional costs of mitigation. Firstly, there are the medical costs of those requiring short-term hospitalization under a mitigation policy. Gros (2020, Sect. 2.2) assumes that the entire population of a country becomes infected, and estimates that $20 \%$ would require general hospital care at a cost per patient equal to $30 \%$ of GDP per capita, and $25 \%$ of these would also require Intensive Care treatment at a further cost per patient of $60 \%$ of per capita GDP, yielding a total cost equal to $9 \%$ of GDP. However the assumption that everyone in a population would become infected is excessive. Blakely and Wilson (2020) estimate that the infection rate would not exceed $60 \%$ because the epidemic would 
by then peter out through herd immunity, Boyd (2020, p. 3) adopts a base case of $40 \%$ based upon the experience from past pandemics, and Aguas and Corder (2020) estimate it to be even lower. ${ }^{22}$ Furthermore, even if Gros's estimates of the proportion infected requiring medical care were correct, this would (even at a $40 \%$ infection rate) imply $2 \mathrm{~m}$ Australians requiring hospitalization ( $8 \%$ of its population), and 500,000 of these requiring an ICU. However, there would not be enough hospital beds or ICUs in the country or medical staff to cater for even a fraction of them.

By contrast, Bailey and West (2020, Appendix A) estimate hospitalized cases at 960,000 , ICU cases as 256,000, and deaths at 141,000 under a mitigation policy. Since my upper bound on the number of deaths under a mitigation policy is 41,000 , this implies 280,000 hospitalised cases and 74,000 ICU cases. Clearly, the Australian hospital system could not accommodate all of them. Furthermore, whatever number of cases were accommodated, they would be to some degree permanently displacing other types of patients so the incremental costs would be even less. Even without displacement, most of the medical costs would be fixed (staff, buildings, and equipment) and therefore irrelevant. The upper limit on the costs arises if the system could accommodate all cases, there is no displacement of other types of patients, and all costs are variable. Using Gros's costs of $60 \%$ of GDP per capita for ICU cases and $30 \%$ for the rest along with Australia's GDP per capita of $\$ 75,000$, the upper bound on the resulting incremental costs would be $\$ 9.6 \mathrm{~b}$ as follows:

$$
75,000[280,000(0.3)+74,000(0.6)]=\$ 9.6 b
$$

Kompas et al (2020, Sect. 4.3) estimates the costs at $\$ 23.3 \mathrm{~b}$ under their no suppression scenario, which involves 260,000 deaths. Scaled down to reflect the 41,000 deaths forecasted here under a mitigation scenario, the result is $\$ 3.7 \mathrm{~b}$. Using the higher figure of $\$ 9.6 \mathrm{~b}$ to modify Eq. (5), the cost per QALY is now $\$ 1.03 \mathrm{~m}$ as follows:

$$
C=\frac{\$ 175 b-\$ 9.6 b}{160,000}=\$ 1,030,000
$$

Secondly, mitigation gives rise to some survivors who may experience significant long-term adverse consequences. Arnold and Hamilton (2020) report that, amongst Covid-19 cases in the UK who were hospitalized, $26 \%$ died and $74 \%$ of the rest had ongoing problems after 12 weeks, implying a ratio of slow recovery patients to dead of $74 * 0.74 / 26=2.1$. However, this ratio will be too low because it excludes slow recovery patients who were never hospitalized. Using data from the Covid Symptom Study, Couzin-Frankel (2020) estimates that 10-15\% of all of those infected do not recover quickly. More recently, and using the same data source, Greenhalgh and

\footnotetext{
22 Blakely and Wilson (2020) assume a basic reproduction rate of $R_{0}=2.5$ coupled with the classical formula that the "Herd Immunity Threshold" $=1-\left(1 / R_{0}\right)$. This formula overestimates the Herd Immunity Threshold because it assumes no change in behavior by people as the death toll rises. It also assumes that all members of a population are equally exposed to the virus and equally susceptible to it, which is not the case and this implies that herd immunity is achieved at a much lower proportion of the population infected (Aguas et al. 2020).
} 
Knight (2020) estimate that $10 \%$ of those who have tested positive remain unwell after three weeks and a smaller (but unquantified) proportion for months. More recently, in October, and using the same data source, Sudre et al. (2020) estimate that $13.3 \%$ of those who tested positive remained unwell for at least four weeks, with $8.8 \%$ resolved in $4-8$ weeks, a further $2.2 \%$ resolved in 8-12 weeks, and the remaining $2.3 \%$ unresolved after 12 weeks. A pattern consistent with this data is that, amongst this group who are still unwell after 4 weeks, $68 \%$ experience symptoms for $4-8$ weeks, $16 \%$ for $8-12$ weeks, $8 \%$ for $12-16$ weeks, etc. The average time unwell is then

$$
\text { Average }=0.68(6)+0.16(10)+0.08(14)+0.04(18)+\ldots
$$

This series can be decomposed into a set of geometric progressions and then added, to yield an average of 9 weeks (0.16 years). As of 15 October 2020, there were $38.6 \mathrm{~m}$ recorded cases and $1.1 \mathrm{~m}$ deaths worldwide. So, the ratio of these longrecovery Covid-19 cases to deaths is $38.6 \mathrm{~m} * 0.133 / 1.1 \mathrm{~m}=4.7$. Furthermore, consistent with the figure used earlier for Covid-19 victims suffering from serious preexisting conditions, their quality of life is thereby initially reduced by $20 \%$. Allowing for all this is then equivalent to increasing the QALYs saved from lockdown rather than mitigation by $4 \%$ as follows:

$$
\frac{1(5)(0.8)+4.7(0.16)(0.2)}{1(5)(0.8)}=\frac{4.0+0.15}{4.0}=1.04
$$

This raises the denominator in Eq. (6) by a factor of 1.04 . There will also be medical costs associated with these very long-term sufferers. For example, if each such person's medical costs average $\$ 10,000$ per year in which symptoms are experienced, the cost for 193,000 survivors (41,000 victims*4.7) for 0.16 years on average is $\$ 313 \mathrm{~m}$. Both the denominator adjustment of 1.04 and the numerator addition of $\$ 313 \mathrm{~m}$ are too small to warrant inclusion, and alternative (reasonable) assumptions about the time profile of the resolution of these cases and the cost per year per patient do not change this conclusion.

Thirdly, mitigation gives rise to work absences amongst those who are infected and must self-isolate. Gros (2020, Sect. 2.1) assumes all members of a population are infected, $30 \%$ require a work absence of four weeks and a further $20 \%$ require six weeks, leading to a GDP loss of $5 \%$ of one year's GDP:

$$
0.30\left(\frac{4}{52}\right)+.20\left(\frac{6}{52}\right)=0.05
$$

However the assumption that everyone in a population would become infected is excessive. As noted previously, Blakely and Wilson (2020) estimate that the infection rate would not exceed $60 \%$ because the epidemic would by then peter out through herd immunity, Boyd (2020, p. 3) adopts a base case of $40 \%$ based upon past pandemics, and Aguas and Corder (2020) estimates an even lower rate. Furthermore, even if Gros's estimate of $50 \%$ of those infected requiring a work absence were correct, this does not yield a proportionate decline in GDP for various reasons. In particular, many of the people required to isolate could 
still perform their work from home. Furthermore, even where those isolated could not thereby perform their tasks for this period of weeks, other employees of the organization would increase their productivity or hours of work to at least partly compensate, and/or customers of the businesses would experience longer wait times with no loss of output, and/or the absent employees would be able to perform at least some of the work upon their return in addition to their normal workloads. Accordingly, a more reasonable estimate of the GDP loss than Gros's would involve $40 \%$ of the population being infected, and $30 \%$ of those requiring isolation able to still perform their jobs at home, and $75 \%$ of the rest having their work performed by others or by them upon their return to work or addressed through longer customer queues. The resulting GDP loss would then be only $5 \% * 0.4 * 0.7 * 0.25=0.35 \%$ rather than $5 \%$ of one year's GDP. In dollar terms this is $\$ 1950 \mathrm{~b} * 0.0035=\$ 6.8 \mathrm{~b}$. Modifying Eq. (6), the cost per QALY saved would be at least $\$ 990,000$ as follows:

$$
C=\frac{\$ 175 b-\$ 6.8 b-\$ 9.6 b}{160,000}=\$ 990,000
$$

This figure is too low for three principal reasons. Firstly, the estimate of 160,000 QALYs saved by locking down is likely to be too high because it uses the highest estimate of additional deaths from locking down (from the European data). Secondly, the estimate of $\$ 175 b$ for the GDP losses from the lockdowns is too low because the two real GDP forecast paths in Table 2 have not converged over the period for which the forecasts are available (out to mid 2025).

Thirdly, no allowance has been made for various phenomena that would raise the costs of lockdowns but cannot readily be quantified: problems arising from the increased unemployment (addiction, crime, domestic violence, mental health problems, and premature death), loss of social interactions, increased anxiety, disruption to the education of the Covid-19 student cohort, and the deprival of liberties that people would otherwise enjoy. Lockdowns also disrupt the normal operation of the health care system, leading to deaths that would not otherwise occur (such as people who fail to have cancer screening tests done), but failure to lockdown would also likely saturate the system with Covid-19 cases, leading to deaths amongst other types of patients who have been crowded out. The net effect of this point is very unclear, because it depends inter alia on how quickly a society could expand its health care system to accommodate the increased caseload, but the net short-term effect is likely to be small because the deaths attributed to Covid-19 approximate the excess deaths relative to pre-pandemic forecasts (as discussed in Sect. 2.1).

Foster (2020) attempts to quantify the adverse psychological impact of lockdowns on the average Australian, and concludes that it dominates all other considerations. The estimates are inherently subjective. Nevertheless, I consider the psychological effect of unemployment on the unemployed during the period of unemployment because the numbers of people affected can be estimated. Table 3 shows forecast growth rates for the Labour Force in December 2019 (Australian Treasury (2019, 
Table 3 Employment forecasts

\begin{tabular}{lccccccc}
\hline & $19-20$ & $20-21$ & $21-22$ & $22-23$ & $23-24$ & $24-25$ & Sum \\
\hline Dec 2019 Forecasts & $2.25 \%$ & $2.75 \%$ & $3.0 \%$ & $3.0 \%$ & $3.0 \%$ & $3.0 \%$ \\
Implied Employment & 102.3 & 105.1 & 108.2 & 111.5 & 114.8 & 118.2 & \\
May 2021 Forecasts & $-4.2 \%$ & $6.5 \%$ & $1.0 \%$ & $1.0 \%$ & $1.25 \%$ & $1.25 \%$ \\
Implied Employment & 95.8 & 102.0 & 103.0 & 104.1 & 105.4 & 106.7 & \\
Shortfall & 6.5 & 3.1 & 5.2 & 7.4 & 9.4 & 11.5 & 43.1 \\
\hline
\end{tabular}

Table 1.2) and in May 2021 (Australian Treasury, 2021, Table 1.2). ${ }^{23}$ Arbitrarily designating the 2018-19 Labour Force as 100, the Labour Force results are shown under each forecast path, and the shortfall for each year shown in the last row, which aggregates to 43.1, i.e., 43.1\% of Australia's 2018-2019 Labour Force. Since Australia's 2018-2019 Labour Force was $12.9 \mathrm{~m}$, this is the equivalent of $5.6 \mathrm{~m}$ unemployed for one year. ${ }^{24}$ This estimate is conservative because the two Labour Force forecast paths in Table 3 have not converged over the period for which the forecasts are available (out to mid 2025).

Some of these Labour Force shortfalls would have arisen from the pandemic without any lockdowns, and it is only the fraction due to the lockdowns that are of interest. Section 2.3 estimates the proportion of the GDP shortfalls due to lockdowns at $40 \%$, and the same proportion is applied here. So, lockdowns are expected to have reduced the size of the Labour Force by the equivalent of $5.6 \mathrm{~m} * 0.40=2.2 \mathrm{~m}$ for one year, i.e., $2.2 \mathrm{~m}$ people losing their jobs for one year. Frijters (2020) estimates that the loss of employment for one year reduces a person's quality of life during that year by the equivalent of 0.12 years of life. ${ }^{25}$ This estimate is subjective, but so too is the estimate of the reduction in life quality of a typical Covid-19 victim by $20 \%$ to reflect their co-morbidities (in Sect. 2.2 above). In the interests of being very conservative, I halve Fritjers estimate of 0.12 years of life. So, the loss of employment for $2.2 \mathrm{~m}$ people for one year is equivalent to the loss of $2.2 \mathrm{~m} * 0.06=130,000$ QALYs. Netting this off against the 160,000 QALYs saved by the lockdown (at most), and modifying Eq. (7), the cost per QALY saved would be at least $\$ 5.3 \mathrm{~m}$ as follows:

$$
C=\frac{\$ 175 b-\$ 6.8 b-\$ 9.6 b}{160,000-130,000}=\$ 5.3 m
$$

\footnotetext{
23 The figures for 2023-2024 and 2024-2025 do not appear in the document, and are extrapolated from the series for comparison with the later forecasts, which do include 2023-2024 and 2024-2025.

24 For the Labour Force figure, see https://www.abs.gov.au/statistics/labour/employment-and-unemp loyment/labour-force-australia/latest-release.

${ }^{25}$ Frijters (2020) estimates that this loss reduces a person's WELLBYs (a measure of happiness) by 0.7 and the loss of life by a healthy person would reduce WELLBYs by 6. So, the loss of employment for one year is equivalent to the loss of $0.7 / 6=0.12$ years of healthy life.
} 


\subsection{The benchmark valuation of a QALY}

In respect of Australia, Blakely and Wilson (2020) use a benchmark of $\$ 100,000$ per QALY saved, based upon "rules of thumb in the Australian health system". Foster (2020) uses the same figure. By contrast, the WHO recommends a benchmark equal to a country's per capita GDP (Bertram et al. 2016), which is currently $\$ 75,000 .^{26}$ Interestingly, Blakely and Wilson also co-authored an almost identical paper for New Zealand (Blakely, Baker and Wilson 2020), and they adopted a benchmark figure of GDP per capita in that case. In other recent health interventions in Australia, Cheng et al. (2016) used $\$ 50,000$ in assessing cardiac rehabilitation programs as does Kularatna et al. (2020, p. 5) in assessing oral health interventions. Using survey evidence on willingness to pay, Huang et al. (2018) estimate the value at $\$ 22,000-\$ 67,000$ while Lewkowski et al. (2020) estimate it at $\$ 100,000$ for men and $\$ 50,000$ for women. In the interests of being conservative, I favour the largest figure here of $\$ 100,000$.

A related concept is the "Value of a Statistical Life" (VSL), which values all lost years of an average aged person's life. This is recommended in decisions on reducing physical harm, such as in traffic safety and occupational safety, and the current value is $\$ 4.9 \mathrm{~m}$ (Office of Best Practice Regulation 2019, p. 2). This figure is derived from Abelson (2008), who recommends use of its annual equivalent (the Value of a Life Year or VLY: ibid, p. 16), which is performed for a person with a 40-year residual life span using a discount rate of 3\% (ibid, p. 3). Abelson's (2008) use of a 40-year residual life span presumably arose from it representing half of the life expectancy of an Australian (at birth) at that time. This life expectancy is now 41.4 years. ${ }^{27}$ Furthermore, Abelson's discount rate of 3\% presumably reflected market discount rates at that time. These are now considerably lower. In respect of New Zealand, Pharmac (2015, pp. 51-52) recommended that all costs and benefits in health expenditure assessments be discounted by $3.5 \%$ per year, based on the fiveyear average real government bond rate. Following this, I use the average yield on ten-year inflation-indexed Australian government bonds over the last five years (January 2016 to December 2020), of $0.75 \%{ }^{28}$ Applying this discount rate of $0.75 \%$, the VLY would be such that

$$
\$ 4.9 m=\frac{V L Y}{1.0075}+\cdots+\frac{V L Y}{(1.0075)^{41}}
$$

The solution is VLY $=\$ 141,000$. By contrast, the Office of Best Practice Regulation $(2019$, p. 2) recommends $\$ 213,000$, derived using a 40 -year period and a

\footnotetext{
${ }^{26}$ Miles et al (2020, p. 68) reports a guideline figure of 30,000 pounds used in hospitals in the UK (which is close to its 2019 GDP per capita of 32,000 pounds) and the larger figure of $\$ 125,000$ in the US (ibid, p. 72), which is approximately double its 2019 GDP per capita of $\$ 65,000$.

2780.7 years for men and 84.9 for women. See https://www.aihw.gov.au/reports/life-expectancy-death/ deaths-in-australia/contents/life-expectancy.

${ }^{28}$ The RBA reports the yield on these bonds at Table F2: https://www.rba.gov.au/statistics/tables/\#inter est-rates.
} 
discount rate of 3\%. Kompas et al. (2020) uses this latter figure. In choosing between a VLY and the value of a QALY, Gros $(2020$, p. 6) favours the latter because it is the approach that is "practiced routinely by the medical profession" whilst Miles et al. (2020, p. 76) also favours it because it is consistent with the approach to other health expenditures. I concur and therefore favour a QALY value of \$100,000.

Interestingly, some analyses of the Covid-19 issue have been conducted by simply coupling the VSL by the expected number of lives saved rather than coupling the value of a QALY or a VLY with the expected number of (quality adjusted) life years saved (for example, Chapple 2020; Thunstrom et al. 2020; Holden and Preston 2020). This may reflect a belief that Covid-19 victims have a typical average residual life span and perfect health without Covid-19, which may be true in safety interventions but is not the case here, and would therefore significantly overestimate the benefits in QALYs saved. Alternatively, it may reflect their ethical belief that all lives saved are equally valuable, which implies that one would spend as much to extend the life of a person by one day (or even one hour) as one would spend to extend the life of a different person for fifty years. If the latter interpretation is correct, it would be perverse to do so. It would also be inconsistent with prevailing views amongst public health experts in Australia and elsewhere, in which the impact of health interventions on the residual life expectancy of the targets is estimated and converted to a monetary figure using a value per year (Bertram et al. 2016; Cheng et al. 2016; Blakely and Wilson 2020).

\subsection{Comparison of cost with benchmark}

In summary, the cost per QALY saved is at least $\$ 990,000$ if the psychological effects of unemployment are ignored and at least $\$ 5.3 \mathrm{~m}$ if these latter effects are recognized, as shown in Eqs. (7) and (8). Since the benchmark figure is $\$ 100,000$ then the cost per QALY saved significantly exceeds this benchmark figure of $\$ 100,000$, and therefore the March 2020 lockdowns were not justified by the standard methodology. This conclusion is strengthened by numerous additional considerations. Firstly, substituting Blakely and Wilson's (2020) higher estimate of the additional deaths from mitigation (up to 50,000) for the additional 40,000 deaths underlying Eq. (7) does not change the conclusion. Secondly, substituting Bailey and West's (2020) even higher estimate of the additional deaths from mitigation $(114,000)$ for the additional 40,000 deaths underlying Eq. (7) does not change the conclusion. Thirdly, many of the parameter estimates in Eqs. (7) and (8) are towards the end of their probability distributions that yield the lowest possible cost per QALY, most particularly the 160,000 extra QALYs lost from mitigation (likely to be too high) and the $\$ 175$ b GDP loss due to lockdown rather than mitigation (likely to be too low). Fourthly, apart from the allowance within Eq. (8) for the contemporaneous effect on the unemployed from losing their jobs, no allowance has been made for various phenomena that would raise the costs of lockdowns but cannot readily be quantified: more tangible problems arising from increased unemployment (addiction, crime, domestic violence, mental health problems, and premature death), the loss of social 
interactions, increased anxiety, disruption to the education of the Covid-19 student cohort, and the deprival of liberties that people would otherwise enjoy.

The conclusion here might seem to result from the mechanistic application of an economic rule, devoid of ethical considerations. However, consistent application of this rule is necessary to ensure that all quality adjusted life years are treated equally, which in turn derives from the ethical principle of equal treatment of people (appropriately adjusted for differences in their residual life expectancy and the quality of those years).

\section{The merits of lockdown versus mitigation using data available in March 2020}

I now consider the merits of the lockdown decision using data available in March 2020. I focus upon Eq. (7), which does not include the effects of unemployment. The denominator there must be replaced by an estimate derived from contemporaneous data. In mid March 2020, the Australian government believed that the death toll without lockdown would be 50,000 to 150,000, arising from 20 to $60 \%$ of the population being infected and an Infection Fatality Rate of $1 \%$ (see p. 2). A few days later, Blakely and Wilson (2020) estimated the death toll under lockdown at 5000 if successful, that under mitigation at 25,000 to 55,000, and 134,000 dead arising from an infection rate of $60 \%$ of the population if no mitigating actions were taken by the government. This suggests that the Australian government's worst case of 150,000 dead assumed no mitigating actions, and therefore the best estimates in March 2020 of the death tolls under mitigation and lockdown were 40,000 (the midpoint of 25,000 and 55,000) and 5000 respectively. Assuming lockdown was bound to be successful, this implies $(40,000-5000) * 5 * 0.8=140,000$ QALYs saved by locking down. The medical costs in the numerator of Eq. (7) must also be raised to be consistent with the revised denominator value. Kompas et al. (2020, Sect. 4.3) estimates them at $\$ 23.3 b$ under a worst-case death toll of 260,000 . Scaled to reflect 35,000 additional deaths rather than their worst case, these costs fall to $\$ 3.1 \mathrm{~b}$.

In addition, GDP forecasts are required for March 2020 and from the same source just before the pandemic struck. The Australian Treasury provides forecasts only six monthly, in July and December. By contrast, the RBA provides forecasts every 3 months, and the relevant ones are for November 2019, February 2020 and May 2020. The first of these predates the pandemic, the second recognizes some Australian GDP losses from the pandemic but only due to the spillover from its impact on China (RBA 2020a, Chapter 5), whilst the third fully recognizes the effect of the pandemic on Australia (RBA 2020b, Chapter 6). I use the May 2020 forecasts as a proxy for views in March, along with the November 2019 forecasts. For the years ended June 2020, 2021 and 2022, the November 2019 forecasts are 2.5\%, 3\% and 3\% (RBA 2019, Table 5.1), whilst the May 2020 forecasts for the same years are 
- 8\%, 7\% and 5\% respectively (RBA 2020b, Table 6.1). ${ }^{29}$ Using these to estimate the GDP shortfall in the same way as Table 2, the result is a shortfall of $21.5 \%$ of 2019 GDP. Since Australia's 2018-2019 GDP was $\$ 1950 \mathrm{~b}$, this is $\$ 420 \mathrm{~b} .{ }^{30} \mathrm{I}$ attribute $40 \%$ of this to the lockdown, as in Sect. 2.3, to yield $\$ 168 \mathrm{~b}$. This estimate is conservative because the two real GDP forecast paths here have not converged over the period for which the forecasts are available (out to mid 2022). Substitution of these parameter values into Eq. (7) yields a cost per QALY saved of \$1.1 m as follows:

$$
C=\frac{\$ 168 b-\$ 6.8 b-\$ 3.1 b}{140,000}=\$ 1.1 \mathrm{~m}
$$

So, the cost per QALY saved is 11 times the benchmark value of $\$ 100,000$. This strongly favoured mitigation in March 2020. Allowing for the possibility that the lockdowns would fail (Blakely and Wilson 2020, ascribed a 75\% probability to this), the cost per QALY saved would be even higher and therefore mitigation would be even more strongly favoured. For example, if the probability of the lockdowns failing were $50 \%$, the expected death toll from the lockdowns would be $5000 * 0.5+40,000 * 0.5=22,500$, implying an expected saving in lives from the lockdowns rather than mitigation of $40,000-22,500=17,500$, which implies $17,500 * 5 * 0.8=70,000$ QALYs saved by the lockdowns. This halves the denominator in the last equation, which doubles the cost per expected QALY saved to $\$ 2.2 \mathrm{~m}$.

This leaves the question of why the Australian government chose to undertake lockdowns in March 2020. A natural candidate for explaining this is that it was extremely risk averse, i.e., it focused upon the worst case death toll from mitigation over lockdown, of 150,000-5000, which implies 580,000 QALYs saved by locking down. Substituting this into the denominator of the last equation, and scaling up the medical costs consistent with this incremental death toll of 145,000 (from $\$ 3.1 \mathrm{~b}$ to $\$ 13.0 \mathrm{~b})$, the cost per QALY falls to $\$ 250,000$ :

$$
C=\frac{\$ 168 b-\$ 6.8 b-\$ 13 b}{580,000}=\$ 250,000
$$

Even this is above the benchmark of $\$ 100,000$. So, even extreme risk-aversion does not fully explain the government's decision to undertake lockdowns.

A complementary possibility is that the Australian government was also prepared to pay more than the worst-case scenario just described (at the conventional price of $\$ 100,000$ per QALY saved) to buy 'peace of mind' insurance for the whole population. Assuming that lockdowns would succeed, the additional payment would be $P$ satisfying the following equation:

$$
\frac{\$ 168 b-P-\$ 6.8 b-\$ 13 b}{580,000}=\$ 100,000
$$

\footnotetext{
29 The November 2019 forecasts do not provide a forecast for the year ended June 2022, and the forecast for the year ended December 2021 is used as a proxy for it.

${ }^{30}$ The GDP figure comes from Table H1 on the website of the RBA: https://www.rba.gov.au/statistics/.
} 
The solution is $P=\$ 90 \mathrm{~b}$, i.e., the Australian government was prepared to pay $\$ 90 \mathrm{~b}$ in addition to the payment consistent with applying the usual QALY benchmark to the worst case death toll scenario under mitigation coupled with lockdowns being successful. Doing this is not consistent with standard methodology in assessing health interventions, and therefore with the ethical principle of equity. Furthermore, peace of mind benefits are not unique to pandemics, as virtually all health or safety interventions increase peace of mind for the whole population as well as saving QALYs. For example, the road toll in Australia is currently about 1200 per year, and peaked at 3800 in $1970 .^{31}$ This reduction has come in part through road safety expenditures, which have reduced deaths and therefore increased the peace of mind of every motorist (who is at risk of becoming the next victim). Furthermore, the number of QALYs saved here is at least as great as those from pandemic lockdowns, because pandemics for which lockdowns would be contemplated are very rare. If they arise every (say) 50 years, it is necessary to compare them with savings from road safety measures over 50 years. If such measures save 1000 lives per year, with an average residual life expectancy for the victims of 40 years and perfect health, they save $1000 * 40 * 50=2 \mathrm{~m}$ QALYs over 50 years. This is much more than even the worst case scenario for Covid-19 of 580,000 QALYs saved. Despite this, road safety measures are evaluated purely on the basis of the value of the QALYs saved and not also because they increase peace of mind for the entire population.

In seeking an explanation for the decision to lock down, it is noteworthy that the situation is characterized by several highly unusual features in health and safety interventions. Firstly, the source of the problem was new; the resulting absence of directly relevant historical experience may have led decision makers to fear worst case scenarios beyond even those articulated by expert opinion. Secondly, since the effectiveness of lockdowns could reasonably be expected to fall away quickly with any delay, a decision was required much more quickly than the speed at which governments normally operate and haste generally reduces the quality of decision making. Thirdly, the death toll from failure to lock down would be more highly concentrated in time than most other health and safety interventions, which would exaggerate the emotional perception of the death toll and concentrate responsibility for it upon the decision makers, especially since the media gave Covid-19 deaths such attention. Fourthly, the cost of locking down (primarily in the form of GDP losses) would be distributed over several years and therefore would not be attributed entirely to the decision makers. Finally, the unusual form of the most visible cost (GDP losses) lacks the emotional resonance from the more usual monetary payments, and therefore focused decision makers upon the benefits from lockdowns rather than the costs as well as the benefits. The confluence of these factors may have induced the decision to undertake lockdowns, contrary to standard principles of cost-benefit analysis even when using the worst case scenarios articulated by expert opinion.

\footnotetext{
31 See https://en.wikipedia.org/wiki/List_of_motor_vehicle_deaths_in_Australia_by_year.
} 


\section{Looking forward on 5 July 2021}

The analysis to date examines the possibility that mitigation was adopted by Australia in March 2020. Since then, there have been further but more localized lockdowns, and further instances are possible. Assessing the merits of any future lockdowns requires (as before) an estimate of the deaths that would be experienced under a mitigation policy. Such an estimate will be much less than that provided in the previous sections, even if the lockdown covered the same area and was for the same duration, for three reasons. Firstly, the period over which the virus could then inflict casualties would be much less, i.e., from the point in time at which it erupts (after 28 June 2021) until mass vaccination (of high-risk groups) is completed in several months, rather than from March 2020 until this mass vaccination point. Secondly, the vaccination campaign to date and over the period until mass vaccination is achieved will further reduce the death toll. Thirdly, policy and medical lessons have been learned since the first lockdowns that will further reduce deaths if a mitigation policy is adopted, such as the importance of quarantining rest homes, the best use of ventilators, the importance of prone positioning, and improvements in contact tracing and testing. In addition, the GDP losses from such a lockdown will be less than the lockdowns commencing in March 2020 (\$175b), but the reduction should be less pronounced than for the deaths because GDP losses are strongly tilted towards the lockdown period whilst the lives saved by lockdowns are more evenly spread over time until the mass vaccination point.

To illustrate these points, suppose that mass vaccination of high-risk groups will be completed at the end of 2021. Suppose further that a new outbreak occurs now that cannot be contained without a nation-wide lockdown, and adoption of a mitigation policy in response to it is expected to incur additional deaths (relative to a lockdown policy) equal to $28 \%$ of those incurred if a mitigation policy had been adopted in March 2020, because the period from now till the end of 2021 is $28 \%$ of the time period from March 2020 till the end of 2021. Since the additional deaths under the latter scenario (mitigation from March 2020) have been estimated at up to 40,000, the additional deaths under the former scenario (mitigation from the present time) are estimated at $28 \%$ of this, i.e., up to 11,000 . The QALY losses from these additional deaths will be (as before) four times the number of deaths. In addition, suppose the medical costs for sufferers ( $\$ 9.6 \mathrm{~b}$ above) and GDP losses from those absent from work ( $\$ 6.8 \mathrm{~b}$ above) are scaled down in the same proportion as the deaths, to $\$ 2.7 \mathrm{~b}$ and $\$ 1.9 \mathrm{~b}$ respectively. Finally, suppose that GDP losses from this future lockdown will be $50 \%$ of the March 2020 lockdown, i.e., \$88b. With no allowance for the effects of unemployment, the cost per QALY saved through a lockdown rather than mitigation follows Eq. (7) and would then be at least $\$ 1.9 \mathrm{~m}$ as follows:

$$
C=\frac{\$ 88 b-\$ 1.9 b-\$ 2.7 b}{11,000(5) 0.8}=\$ 1.9 m
$$

This is double the result in Eq. (7), and therefore favours a mitigation policy for future outbreaks even more strongly than in March 2020. If vaccinations to date, those to come over the time until mass vaccination is completed, and the policy and 
medical lessons learned since March 2020 reduce the death toll by a further $50 \%$, the denominator in (9) falls by that proportion, raising the ratio to $\$ 3.8 \mathrm{~m}$, thereby favouring mitigation even more strongly.

By contrast, if an outbreak could be contained through locking down only part of the country (local lockdown), the GDP losses from doing so would be only some fraction $(P)$ of the $\$ 88 \mathrm{~b}$ in Eq. (9) whilst all other terms would be unchanged (because locking down any part of the country to prevent an outbreak that would otherwise spread to the entire country would warrant the same values for these other terms as for a nationwide lockdown). The cost per QALY saved by the local lockdown would then be as follows:

$$
C=\frac{P \$ 88 b-\$ 1.9 b-\$ 2.7 b}{11,000(5) 0.8}
$$

Thus, if $P=0.10$, this cost would be $\$ 95,000$, which is below the threshold of $\$ 100,000$. So, the local lockdown would then be justified. In fact, the local lockdown would be justified for any value of $P$ up to 0.10 , i.e., a lockdown affecting a part of the country generating up to $10 \%$ of GDP would be warranted.

This analysis assumes that, if a lockdown occurs at some future point, only one such lockdown will be required before mass vaccination of the high-risk groups occurs. If more than one may be required, then the GDP loss of $P \$ 88 \mathrm{~b}$ in the last equation would be increased. For example, if there were a $50 \%$ probability of a second lockdown affecting the same proportion of the country, the last equation would become

$$
C=\frac{P \$ 88 b(1.5)-\$ 1.9 b-\$ 2.7 b}{11,000(5) 0.8}
$$

The lockdown policy would only then be justified if $P$ were less than 0.07 . Alternatively, if there were a $25 \%$ probability of a second lockdown affecting the entire country, the last equation would become

$$
C=\frac{P \$ 88 b+\$ 88 b(0.25)-\$ 1.9 b-\$ 2.7 b}{11,000(5) 0.8}
$$

The lockdown policy would not then be justified for any value for $P$. All of this demonstrates that locking down only part of the country to contain an outbreak might seem justified, but much less so if one allows for the possibility of future outbreaks.

\section{Conclusions}

This paper has conducted a cost-benefit analysis (otherwise called a cost-effectiveness analysis) of Australia's Covid-19 lockdown strategy relative to pursuit of a mitigation strategy in March 2020. The estimated additional deaths from a mitigation policy are 11,500 to 40,000. The result is that the cost per Quality Adjusted 
Life Year saved by locking down is estimated to be at least 11 times the generally employed figure of $\$ 100,000$ for health interventions in Australia. The lockdowns were therefore not justified by the standard methodology. Consideration of the information available to the Australian government in March 2020 yields a similar ratio and therefore strongly supported adoption of a mitigation strategy at that time. If Australia experiences a new outbreak, and cannot contain it without resort to a nationwide lockdown, the death toll from adopting a mitigation strategy at this point would be even less than had it done so in March 2020 due to the vaccination campaign, lessons learned since March 2020, and because the period over which the virus would then inflict casualties would now be much less than the period from March 2020. This would favour a mitigation policy even more strongly than in March 2020. This approach of assessing the savings in quality adjusted life years and comparing them to a standard benchmark figure ensures that all quality adjusted life years saved by various health interventions are treated equally, which accords with the ethical principle of equity across people.

\section{Appendix}

This Appendix examines the possibility of reverse causality in Eq. (1), i.e., causality runs from $D$ to $S$ (as well as $S$ to $D$ ), because of one or both of the following:

(a) Some governments chose their $S$ value at the commencement of the crisis based upon their predictions of $D$ under both low and high $S$ scenarios. In particular, governments that predicted only moderately higher death rates under mitigation than under lockdowns may have been inclined to adopt a mitigation policy whilst those predicting much higher death rates under mitigation than lockdown may have been inclined to lock down.

(b) Some governments chose their $S$ values based upon their observation of their country's death rate in the early stages of the crisis.

If either of these is true, the estimated coefficient on $S$ in Eq. (1) may be biased. The traditional method of dealing with this is to use an "instrumental variable", but no good candidates are apparent. I therefore enquire into the extent of these problems.

In respect of the first possible problem, I will focus upon the death rates under mitigation $(S=50)$ and extreme lockdown $(S=100)$. Suppose that there are two types of countries (A and B) whose governments held the views shown in Table 4 (at the commencement of the crisis) about expected death rates (per $1 \mathrm{~m}$ ) under mitigation and extreme lockdown.

Type A countries choose $S=100$ because the expected death rate is unacceptably high with $S=50$, yielding $D=300$. Type B countries have much lower expected death rates than type A countries under both mitigation and extreme lockdown, and choose $S=50$ because the expected death rate in that scenario is acceptable, yielding $D=250$. If the governments' predictions are on average accurate, then regressing 
$D$ on $S$ would then be expected to yield a coefficient on $S$ of 1.0. However, the true coefficients on $S$ are much lower: -34.0 for type A countries and -2.5 for type B countries. Thus, the regression coefficient on $S$ would be biased upwards.

It is plausible that some governments believed that their death rate under mitigation would be both large and vastly in excess of their death rate under extreme lockdown, as shown in Table 4, and acted accordingly in accordance with the predictions of experts like Ferguson et al. (2020). It is also plausible that other governments believed that their death rates under mitigation would be much lower, as shown in Table 4, and acted accordingly in accordance with contrary expert opinions. ${ }^{32}$ However, both types of governments' beliefs would need to be (on average) correct in order to be compatible with the expected coefficient on $S$ in a regression like Eq. (1). Thus, there would have to be features of these two types of countries that would justify the markedly higher death rate in type A countries than in type B countries under mitigation (eight times larger, as in Table 4), and governments would have to have been capable of recognizing these at the commencement of the crisis. Experts' predictions, such as those of Ferguson et al. (2020), would not have helped. For example, Ferguson et al. (2020) used Chinese data to generate predictions for only the UK and US, which differed only slightly (3700 per $1 \mathrm{~m}$ for the UK and 3500 for the US) due to demographics and population density (ibid, pp. 6-7, 16). Furthermore, their numerous critics believed their death rates for the UK and US under mitigation were too high rather than that they were correct for those countries but far too high for others. Furthermore, if by some other means, governments believed that their death rates under mitigation would markedly differ due to some variable other than the regressors used in Eq. (1) or those tested and rejected here, and their beliefs were correct, they would have to have been aware in advance of a variable that I have not been able to locate even with the advantage of subsequently obtaining and testing the data that has become available since the commencement of the crisis. These conditions are not plausible, and this implies that the estimated coefficient on $S$ in Eq. (1) is not materially biased for reasons of this type.

The second potential source of reverse causality in Eq. (1) is that some governments may have chosen their $S$ values in light of their observation of their country's death rate in the early stages of the crisis, believing it would predict the final death rate. To illustrate this, suppose there are two types of countries, with average death rates under mitigation and extreme lockdown as shown in Table 5. At the commencement of the crisis, it is unknown which category each country lies in but it is revealed by the death rates in the early stages of the crisis. So, upon observing their early stage death rates, the governments of type A countries then understood that they were of that type and chose extreme lockdown, yielding $S=100$ and an average death rate of $D=300$. At the same point, the governments of type B countries then understood that they were of that type and chose mitigation, yielding $S=50$ and an average death rate of $D=250$. Regressing $D$ on $S$ would then be expected to yield a coefficient on $S$ of 1.0. However, the real coefficients on $S$ are much lower: -6.0 for

\footnotetext{
32 See for example https://thehill.com/opinion/healthcare/489962-what-if-the-sky-is-falling-coronavirusmodels-are-simply-wrong.
} 
Table 4 Expected death rates under various scenarios

\begin{tabular}{lll}
\hline & $S=50$ & $S=100$ \\
\hline Country A & 2000 & 300 \\
Country B & 250 & 125 \\
\hline
\end{tabular}

type A countries and -2.5 for type B countries. Thus, the regression coefficient on $S$ would be biased up.

This scenario can be tested as follows. For each country, I regress its Stringency value ten days after its first reported death $\left(S_{10}\right)$ on its death rate up to that point $\left(D_{10}\right)$, to assess whether $D_{10}$ can explain $S_{10}$. I repeat the process for 20 and 30 days after each country's first death. I also test whether any of these three early stage death rates can explain the maximum $S$ value chosen by governments $\left(S_{m}\right)$. These regressions yield the results shown in the first six columns of Table 6 below. Only two of these regressions even yield a positive coefficient on early death rate (consistent with the scenario in Table 5) and none of them yields a statistically significant coefficient on it. So, the hypothesis that early stage death rates did not affect governments' choice of $S$ cannot be rejected. This is surprising because the death rates up to day 20 , and even more so for up to day 30 , are good predictors of the death rate in the first wave of the crisis (to 22 August 2020, and designated $D$ ), as shown in the last three columns of Table 6 . So, at least from day 20 , the death rate data up to that point could have been used to set the $S$ value at that point or the maximum $S$ value but governments did not seem to have done so.

This raises the interesting question of what does then explain the maximum $S$ values. Regressing this variable on the variables used in or tested for inclusion in Eq. (1), including population density, date of first death, and household size, yielded no statistically significant coefficients. However, ranking the maximum $S$ values from highest to lowest reveals that the four countries arising from the breakup of Yugoslavia occupy four of the 'top' six slots (with an average $S$ value of 95) and the five Scandinavian countries occupy four of the 'bottom' five slots (and have an average $S$ value of 68). This suggests that the $S$ choice was in part driven by mimicry of neighbouring countries. Consistent with this, Sebhatu et al. (2020) finds that the speed with which restrictions were adopted by the OECD members was influenced by the behavior of nearby countries.

In summary, the cross-sectional regression in Eq. (1) does not seem to suffer from reverse causality from $D$ to $S$. 
Table 5 Average death rates under various scenarios

\begin{tabular}{lll}
\hline & $S=50$ & $S=100$ \\
\hline Country A & 600 & 300 \\
Country B & 250 & 125 \\
\hline
\end{tabular}

Table 6 Stringency levels and death rates

\begin{tabular}{llllllllll}
\hline Dep Var (DV) & $S_{10}$ & $S_{20}$ & $S_{30}$ & $S_{m}$ & $S_{m}$ & $S_{m}$ & $D$ & $D$ & $D$ \\
Indep Var (IV) & $D_{10}$ & $D_{20}$ & $D_{30}$ & $D_{10}$ & $D_{20}$ & $D_{30}$ & $D_{10}$ & $D_{20}$ & $D_{30}$ \\
\hline Mean DV value & 68 & 77 & 79 & 81 & 81 & 81 & 198 & 198 & 198 \\
Mean IV value & 3 & 17 & 50 & 3 & 17 & 50 & 3 & 17 & 50 \\
Coeff on DV & 1.9 & -0.07 & 0.002 & -0.57 & -0.10 & -0.02 & 7.8 & 7.4 & 2.8 \\
$P$ Value for DV & 0.09 & 0.59 & 0.96 & 0.37 & 0.37 & 0.52 & 0.53 & 0 & 0 \\
Adjusted $R^{2}$ & 0.06 & -0.02 & -0.03 & -0.01 & -0.01 & -0.02 & -0.02 & 0.40 & 0.66 \\
\hline
\end{tabular}

Acknowledgements Helpful comments from the following people are gratefully acknowledged: Hai Lin, Arthur Grimes, Lyndon Moore, Glenn Boyle, Amanda Breton, Paul Calcott, Robert Kirkby, Eric Crampton, John Gibson, Dave Heatley, Shaun Hendy, Mark Johnson, Michael Reddell, Jack Robles, and Adrian Slack. Agreement with the conclusions is not implied. The helpful comments of the two anonymous referees are also gratefully acknowledged.

\section{References}

Abelson, P. 2008. Establishing a monetary value for lives saved: Issues and controversies. Office of Best Practice Regulation. https:/www.pmc.gov.au/sites/default/files/publications/Working paper_2_Peter_Abelson.pdf.

Aguas, R., and R. Corder. 2020. Herd immunity thresholds for SARS-CoV-2 estimated from unfolding epidemics. medRxiv. https://doi.org/10.1101/2020.07.23.20160762v2.

Andersen, A., E. Hansen, N. Johannesen, and A. Sheridan. 2020. Pandemic, shutdown, and consumer spending: Lessons from scandinavian policy responses to Covid-19. https://arxiv.org/pdf/2005. 04630.pdf.

Argarwal, V., J. Cantor, N. Sood, and C. Whaley. 2021. The impact of the COVID-19 pandemic and policy responses on excess mortality. NBEr Working Paper 28930. https://www.nber.org/system/ files/working_papers/w28930/w28930.pdf.

Arnold, D., and F. Hamilton. 2020. Patient outcomes after hospitalisation with Covid-19 and implications for follow-up: Results from a prospective UK Cohort. https:/www.medrxiv.org/content/ medrxiv/early/2020/08/14/2020.08.12.20173526.full.pdf.

Aum, S., S. Lee and Y. Shin. 2020. Covid-19 doesn't need lockdowns to destroy jobs: The effect of local outbreaks in Korea. NBER working paper. https://www.nber.org/system/files/working papers/w27264/w27264.pdf.

Australian Treasury. 2019. Mid-Year Economic and Fiscal Outlook 2019-20. https://budget.gov.au/ 2019-20/content/myefo/download/01_Part_1.pdf.

Australian Treasury. 2021. Budget strategy and outlook: Budget paper No. 1 2021-22. https://budget. gov.au/2021-22/content/bp1/download/bp1_2021-22.pdf. 
Bailey, N., and D. West. 2020. Are the Covid19 restrictions really worth the cost. https://arxiv.org/ $\mathrm{abs} / 2005.03491$.

Beaudet, A., J. Clegg, P. Thuresson, A. Lloyd, and P. MacEwan. 2020. Review of utility values for economic modelling in type 2 diabetes. Value in Health 17: 462-470.

Bertram, M., J. Lauer, and S. Hill. 2016. Cost-effectiveness thresholds: Pros and cons. Bulletin of the World Health Organisation 94: 925.

Blakely, T., and N. Wilson. 2020. The maths and ethics of minimising Covid-19 deaths. https://pursu it.unimelb.edu.au/articles/the-maths-and-ethics-of-minimising-covid-19-deaths.

Blakely, T., Baker, M., and Wilson, N. 2020. The maths and ethics of minimising Covid-19 deaths in NZ. Public Health Expert 23/3/2020 https://sciblogs.co.nz/public-health-expert/2020/03/23/themaths-and-ethics-of-minimising-covid-19-deaths-in-nz/.

Boyd, M. 2020. The stakes of mismanaging Covid-19: Modelling the possible health system and longterm economic impacts in New Zealand using treasury's CBAX method. Working paper https:// adaptresearch.files.wordpress.com/2020/03/200318_v2_manuscript-modelling-the-economicimpact-of-covid_19.pdf.

Briggs, A. 2020. Moving beyond 'Lives-Saved' from Covid-19. https://avalonecon.com/ moving-beyond-lives-saved-from-covid-19/.

Caselli, F., F. Grigoli, and D. Sandri. 2021. Protecting lives and livelihoods with early and tight lockdowns. Covid Economics 66: 37-55.

Chapple, S. 2020. Covid-19: How much is a NZ life worth. Ideasroom. https://www.newsroom.co.nz/ ideasroom/2020/03/17/1087345/how-much-is-a-nz-life-worth.

Chaudhry, R., G. Dranitsaris, and T. Mubashir. 2020. A country level analysis measuring the impact of government actions, country preparedness and socioeconomic factors on Covid-19 mortality and related health outcomes. E Clinical Medicine 25: 100464.

Cheng, Q., J. Church, M. Haas, S. Goodall, J. Sangster, and S. Furber. 2016. Cost-effectiveness of a population-based lifestyle intervention to promote healthy weight and physical activity in non-attenders of cardiac rehabilitation. Heart Lung and Circulation 26: 265-274.

Couzin-Frankel, J. 2020. from brain fog to heart damage. Science Magazine, https://www.sciencemag. org/news/2020/07/brain-fog-heart-damage-covid-19-s-lingering-problems-alarm-scientists.

Doti, J. 2021. Benefit-cost analysis of Covid-19 policy intervention at the state and national level. Covid Economics 67: 94-127.

Ferguson, N. et al. 2020. Impact of non-pharmaceutical interventions to reduce Covid-19 mortality and healthcare demand. Working paper https://www.imperial.ac.uk/media/imperial-college/medicine/ sph/ide/gida-fellowships/Imperial-College-COVID19-NPI-modelling-16-03-2020.pdf.

Foster, G. 2020. Submission to the Victorian Parliament. https://parliament.vic.gov.au/images/stories/ committees/paec/COVID-19_Inquiry/Tabled_Documents_Round_2/CBA_Covid_Gigi_Foster.pdf.

Frijters, P. 2020. How many WELLBYs is the corona panic costing. https://clubtroppo.com.au/2020/04/ 08/how-many-wellbys-is-the-corona-panic-costing/.

Gibson, J. 2020. Hard, not early: Putting the New Zealand Covid-19 response in context. Working paper, University of Waikato.

Gomez-Pineda, J. 2020. Growth forecasts and the Covid-19 recession they convey: End-2020 update. Covid Economics 62: 66-73.

Goolsbee, A., and C. Syverson. 2020. Fear, lockdown and diversion: Comparing drivers of pandemic economic decline 2020. SSRN working paper, https://papers.ssrn.com/sol3/papers.cfm?abstract_ $\mathrm{id}=3631180$.

Greenhalgh, T., and M. Knight. 2020. Management of post-acute Covid-19 in primary care. BMJ 370: $\mathrm{m} 3026$.

Gros, D., 2020. The great lockdown: Was it worth it?. Policy Insights May 2020, https://www.ceps.eu/ wp-content/uploads/2020/05/PI2020-11_DG_The-great-lockdown.pdf.

Hale, T., N. Angrist, B. Kira, A. Petherick, T. Phillips, and S. Webster. 2020a. Variation in government responses to Covid-19, Working paper, University of Oxford. https://www.bsg.ox.ac.uk/sites/defau 1t/files/2020-05/BSG-WP-2020-032-v6.0.pdf.

Hale, T., A. Hale, B. Kira, A. Petherick, T. Phillips, D. Sridhar, R. Thompson, S. Webster, and N. Angrist. 2020b. Global assessment of the relationship between government response measures and Covid-19 deaths. medRxiv. https://doi.org/10.1101/2020.07.04.20145334v1.

Holden, R., and B. Preston. 2020. The costs of the shutdown are overestimated. https://theconvers ation.com/the-costs-of-the-shutdown-are-overestimated-theyre-outweighed-by-its-1-trillion-benef it-138303. 
Hope, C. 2020. Covid-19 Death Rate is Higher in European Countries with a Low Flu Intensity Since 2018, Cambridge Judge Business School working paper 03/2020. https://www.jbs.cam.ac.uk/wpcontent/uploads/2020/08/wp2003.pdf.

Huang, L., P. Fritjers, K. Dalziel, and P. Clarke. 2018. Life satisfaction, QALYs, and the monetary value of health. Social Science \&amp; Medicine 211: 131-136.

IMF. 2020. World Economic Outlook, October 2020: A Long and Difficult Ascent. https://www.imf.org/ en/Publications/WEO/Issues/2020/09/30/world-economic-outlook-october-2020.

Kompas, T., R. Grafton, T. Che, L. Chu, and J. Camac. 2020. Health and economic costs of early, delayed and no suppression of Covid-19: The case of Australia. medRxiv. https://doi.org/10.1101/2020.06. 21.20136549v1.full.pdf.

Kularatna, S., R. Lalloo, and N. Johnson. 2020. Demonstration of high value care to improve oral health of a remote indigenous community in Australia. Health and Quality of Life Outcomes 18: 1-10.

Lewkowski, K., L. Fritschi, J. Heyworth, D. Liew, and I. Li. 2020. Productivity burden of occupational non-induced hearing loss in Australia. International Journal of Environmental Research and Public Health 17: 4667.

Miles, D., M. Steadman, and A. Heald. 2020. Living with Covid-19: balancing costs against benefits in the face of the virus. National Institute Economic Review 253: R60.

Moss, R., J. Wood, and J. McVernon. 2020. Modelling the impact of Covid-19 in Australia to inform transmission reducing measures and health system preparedness. Medrxiv. https://doi.org/10.1101/ 2020.04.07.20056184v1.full.pdf.

NHS. 2018. National Diabetes Audit 2017-2018 Report 2a: Complications and Mortality. https://files. digital.nhs.uk/91/084B1D/National\%20Diabetes\%20Audit\%2C\%202017-18\%2C\%20Report\%202a. pdf.

Office of Best Practice Regulation. 2019. Best practice regulation guidance note value of a statistical life. https://www.pmc.gov.au/sites/default/files/publications/value-of-statistical-life-guidance-note_0_0. pdf.

Pharmac. 2015. Prescription for pharmacoeconomic analysis: Methods for cost utility analysis. https:// www.pharmac.govt.nz/assets/pfpa-2-2.pdf.

Pujol, T. 2020. The long-term economic costs of Covid-19 in the consensus forecasts. Covid Economics 44: 225-240.

RBA. 2019. Statement on Monetary Policy - November 2019. https://www.rba.gov.au/publications/smp/ 2019/nov/pdf/05-economic-outlook.pdf.

RBA. 2020a. Statement on Monetary Policy - February 2020. https://www.rba.gov.au/publications/smp/ 2020/feb/.

RBA. 2020b. Statement on Monetary Policy - May 2020. https://www.rba.gov.au/publications/smp/2020/ may/.

Scherbina, A. 2021. Could the United States benefit from a Lockdown? A Cost-Benefit Analysis. Covid Economics 65: 78-107.

Sebhatu, A., K. Wennberg, S. Arora-Jonsson, and S. Lindberg. 2020. Explaining the homogeneous diffusion of COVID-19 nonpharmaceutical interventions across heterogeneous countries. Proceedings of the National Academy of Sciences 117: 21201.

Stern, C., and D. Klein. 2020. Stockholm City's Elderly Care and Covid-19, forthcoming in Society. https://papers.ssrn.com/sol3/papers.cfm?abstract_id=3609493.

Sudre, C., B. Murray, and C. Steves. 2020. Attributes and predictors of long-Covid. Medrxiv. https://doi. org/10.1101/2020.10.19.20214494v1.

Szende, A., B. Janssen, and J. Cabases. 2014. Self-reported population health: An international perspective based on EQ-5D. New York: Springer.

Thunstrom, L., S. Newbold, D. Finnoff, M. Ashworth, and J. Shogren. 2020. The benefits and costs of using social distancing to flatten the curve for Covid-19. Journal of Benefit-Cost Analysis 11 (2): $179-195$.

Publisher's Note Springer Nature remains neutral with regard to jurisdictional claims in published maps and institutional affiliations. 